\section{Briginal alrtixles.}

\section{THE ASYLUMS OF EUROPE. 1}

BY GEORGE M. BEARD, A. M., M. D., NEW YORK.

WhILE visiting Europe during the past summer I had occasion to study the asylums and the asylum systems of Great Britain, France, and Germany.

My method of investigation was to visit certain representative institutions, especially those that are supposed to be most advanced in their ideas of the treatment of the insane, but not to confine myself to those exclusively; and to converse with physicians and superintendents who had made themselves acquainted with the methods of managing asylums in their respective countries.

In studying these institutions I did not usually avail myself of any letters of introduction, nor did I give any preliminary announcement of my coming, nor was the special object of my visit always stated until the visit was completed.

Offers of introduction from men of the highest influence in this department met me, but $I$ had no occasion to accept them. I wished to see the asylums as they were in their actual and average daily life; in undress rather than in dress parade.

In some cases I saw the chiefs of the institutions, in others assistants or subordinates, in others still only the chief attendants.

In England and Scotland all classes of the insane are under governmental supervision, and they are visited regularly by the officials, without any warning, whether contined in public or in private asylums. I inspected, therefore, the places that represented all these different modes of caring for the insane, - public institutions, those partly public and partly private, and those entirely private. I also spent twordays at the home of Wickham Barnes, Esq., who resides near London, and who for many years has had in his house an insane patient who is regularly called upon by the commissioners in lunacy. Places like Gheel and Hanwell, and the West Riding asylums have been so often described that it did not seem necessary to go to them.

Among the institutions I visited were Saughton Hall Asylum, near Edinburgh, under the charge of J. Butty Tuke, M. D. ; the Royal Edinburgh Asylum, under charge of T. S. Clouston, M. D. ; Faulborn Asylum, near Cambridge, under charge of Dr. G. M. Bacon ; St. Ann's Asylum, Paris ; Asylum for the Insane at Munich, under charge of Dr. Gudden; the asylums at Vienna and Prague; and, lastly, the institution that is now exciting so much attention in Germany, at Alt Scherbitz, near Leipsic. I visited ten places where the insane are cared for.

Everywhere I was treated with all the kindness and courtesy that I could ask; not only was I shown through the institutions thoroughly, but my cross-examinations in order to get at the modes of treatment, methods of restraint, and general management of the institutions, were always pleasantly responded to on the part of those with whom I was brought into relation.

Assistance of the most valuable character I derived from conversations with Dr. Crichton Browne, formerly of West Riding Asylum, and now one of the Chancellor's Visitors in Lunacy, and who is therefore situated

1 Read before the meeting of the National Association for the Protection of the Insane, at Fifth Avenue Hotel, New York, November 11,1880 . so as to know as well as any one possibly can the pres. ent condition and the prospects of the asylum systems of England. By his suggestion I obtained a copy of the lunacy laws prepared by Danby P. Fry, Esq., and containing all the statutes relating to Private Lunatics, Pauper Lunatics, Criminal Lunatics, Commissions of Lunacy, Public and Private Asylums, and the Commissioners of Lunacy.

From this volume and my conversations with Dr. Browne, I obtained points which were more or less new to me, and which have aided me in reaching the conclusions I am here presenting. These conclusions, stated as briefly as possible, are as follows:-

First. In the methods of supervision and in the general care of insane in public and private asylums Great Britain has been easily first of all nations. Next to Great Britain comes Germany, which, however, is so fast improving that she soon may be on an equality with Great Britain ; of the three British Isles, Scotland on the whole takes the lead of England and Ireland; and it may be positively affirmed that on the average the insane in Scotch asylums are better treated than in any other country. Next to Germany comes France in order of merit.

This relative order of excellence is derived, I may say, not only from my own personal observation, but from extensive inquiries from men best fitted of all to know the true facts on this subject in their respective countries. (For some of these facts I am under especial obligations to Dr. Westphal, of Berlin, who takes much interest in the subject of the treatment of the insane, and by whose suggestions and invitation I visited the institution at Alt Scherbitz. Professor Ball, of Paris, also gave me information of value in reference to the French system and institutions. Dr. Arnold Piek, of Prague, a student of Westphal, interested himself very much in my inquiries. Conversations of this kind with different individuals in different countries, in asylums and out of asylums, I found of quite as much assistance as visiting institutions ; I depended, however, neither upon the one method of gaining information nor upon the other, but as well as I could made use of both.

I may say also that in previous visits to Europe I had seen many of the best known alienists, and year before last had corresponded with them in reference to some of the special topics of which I am here to report.

Secondly. Some method of governmental supervision of the insane appears to be universal, both in Great Britain and on the Continent. Of the four great countries the United States appears to be alone in compelling the insane to depend exclusively upon their atteudants and superintendents and local trustees. The method of central supervision in Great Britain is somewhat complex, but it secures its object, - the guardianship of the insane.

The English commissioners must not only regularly visit the institutions, public and private, but they must visit each insane person who is kept in care for pay in any private house, and these visits must be made without any warning, and they must see the patient when they come, and they must inquire into and report upon the details of his life and treatment. In the case of wealthy patients - so-called chancery lunatics that is, those who have property, inquiries of the most minute character are made: the commissioners are to find out whether the patients have all the cigars they want, all the means of amusement and recreation they 
need; whether anything within their means, however trifling, is left undone that would be for their comfort. For all classes of patients, poor and rich, in asylums the commissioners are guardians, and for everything that has a bearing on their welfare. They are consulted in regard to the plans and sanitary arrangements of buildings; they examine the records and registers of asylums, take care of letters addressed to them by patients, and, so far as possible, see to it that no persons are improperly admitted or retained.

The system of governmental supervision of Scotland differs somewhat from that in England, and would appear, on the side of simplicity, at least, to have some advantages over that of England, but in priuciple it is similar.

Ireland also has a system which in its details is different from that of Scotland or England; but all these countries have a belief in central supervision; neither superintendents of asylums nor any others who have to do with the insane would thisk of doing away with this system of central supervision any more than they would think of doing away with the asylums.

Thirdly. In the best asylums of Europe mechanical restraint is reduced to a very small percentage, and instead of restraint labor is employed as a therapeutic agent. These two facts, absence of restruint and presence of labor, impress one at once on visiting institutions like those, for example, near Edinburgh, or at Alt Scherbitz, near Leipsic. In England and Scotland $I$ found no patient, in restraint, and scarcely any excitement in the wards or grounds.

Padded rooms, and in some cases camisoles, are found in European asylums; but padded rooms are often, if not usually, empty, and the camisoles I did not see in use in any of the English asylums, and but very few in France or Germany.

In one of the German asylums the assistant who took me around pointed out one or two patients with their arms confiued, aud said, "This is not my idea; if $I$ could have my way I would not use these."

The extent to which labor is employed seems incredible, and cross-examinations were constantly needed in order to convince me that not only washing, cooking, cleaning, and the immense farm work on the grounds, but also various trades, were carried on by the inmates, the patients of the asylums. Again and again I asked how they succeeded in making the lunatics work. The average reply was that, in general, there was no serious difficulty; that by proper management they could be trained to work and kept at work, and would do as much as, and, in some cases very much more than, persons in health.

Out of three hundred and forty-seven private and pauper male patients in the West House of the Royal Edinburgh Asylum, two hundred und fifty-four were profitably employed: one hundred and eighty-four in outdoor work, thirty-eight as tradesmen, and thirlytwo as assisting attendants. The difficulty that Dr. Shaw, of the Flatbush Asylum, encountered, that is, the objection of friends of the patients to having their insane friends and relatives compelled to work, is not met with in Europe; so far as I could learn no such prejudice has to be overcome. Of five hundred and forty-one pauper patients in the Royal Edinburgh Asy. lum; of both sexes, only eighteen men and twenty-eight women were prevented by their mental and moral condition from being employed.

This utilization of labor is carried out in detail not only in Fngland, but in France and Germany ; and, as it would seem to me, more thoroughly and successfully in England than in the other countries. At Alt Scherbilz there is a farm, on which the inmates work, and on that and in the shops and in the cooking and washing rooms are carried on almost all forms of labor, - as much as one would see in a good-sized village.

Whatever can be said, or has been said, or will be said to the contrary, the general principle of reducing restraint, or employing it merely in a very small percentage of cases, is not only universal in the best asylums of England, but is growing into favor everywhere in Europe. Among the most thoughtful, scholarly, and advanced men, especially the younger men, both in England and on the Continent, it is no longer a question, but an established principle beyond discussion, the only points raised being those which relate to the degree of restraint, and the best methods to be substituted for it. In these particulars there is not and need not be entire agreement, auy more than there is or need be entire agreement among physicians in regard to any hygienic or therapeutic measure.

Among the best alienists of Europe, those who have dowe and are now doing the most to advance our ideas relating to insanity, theoretically and practically, in and out of asylums, the belief that restraint should be reduced to a minimum is as universal as the belief in the preventive power of vaccination. According to Westphal, non-restraint is the rule in the asylums of $\mathbf{H a m}$ burg, Göttingen, Charité (Berlin), Halle, Marburg, Heidelberg, Eberswalde, Keppenheim, Werneck, Munich, and Alt Scherbitz, and in all the asylums of Switzerland. ${ }^{1}$

Fourthly, In the best asylums of Europe the insane are treated much like children. This principle has not, I believe, been formulated in so many words; but, nevertheless, it is acted upon rationally and instinctively.

All families allow their children liberty, but it is a watched and guarded liberty; we do not chain them, nor shut them up in closets, but suffer them to come and go as they please, and as we please, according to their age, all the time keeping a guardianship over them to see that they do not wander too far away and do not harm themselves or others. The insane are children, diseases of the brain practically depriving them of the advantages that come from education and maturity, taking away their manhood, and carrying them back to childhood ; it is therefore wise to treat them like children. They are not, as a rule, to be chained, or cribbed, or bound, or camisoled, or locked in dark closets, or locked up at all, necessarily, but, like children, allowed to come and go as they please and as we please; all the time watched and guarded. lest they wander away or run away, or do injury to themselves or to society.

Now and then a child must be deprived of this average liberty; now and then a lunatic must be deprived for a time - a few hours or days, or longer, of this average liberty ; but for the great majority there should be, always, the freedom of childhood.

When I visited Saughton Hall institution I asked the gentleman who showed me through the buildings what kept the patients from escaping. "Why," said I, "should they not all be in Edinburgh in half an hour?" He replied that the patients were watched nore carefully than was apparent, and that the number of escapes was comparatively small. The attendants watched 1 Alienist and Neurologist, October, 1880. 
them without appearing to do so; just as we look after our children without keeping them constantly under our eyes, when we know where they are, aud would at once miss them if they should wander. even though they may not know or suspect that we are looking out for them.

The experiment of carrying on a lunatic asylum with unlocked doors, dispensing almost entirely with bolts and bars, is one of the most interesting and important of all the scientific advances that have been made in the treatment of the insane, and both alienists and psychologists would do well to study it. Dr. J. Batty Tuke, of the Saughton Hall institution, near Edinburgh, in his report for 1879 , says that when he was medical superintendent of the Fife and Kinross District Lunatic Asylum he ordered all the doors of the asylum, inside and outside, to be left unlocked, only three wards being excepted, in which thirty out of two hundred and sixty patients resided. As a result of this experiment, there were no accidents and few or no attempted escapes. 'There was greater tranquillity among the patients, and some who had before tried to run away no longer manifested any desire to do so. At first there was a greater anxiety on the part of the officers and attendants, and this anxiety caused them to be more watchful and careful, and, for a time, there was some increase in the number of escapes; but after a f $w$ weeks this anxiety on the part of the officers and the increase in the number of attendants ceased to be necessary, and the doors were not specially watched. 'This system was carried out in the same asylum by Dr. Tuke's successors, Drs. John Fraser and Joseph Brown.

Dr. Arthur Mitchell, commissioner of lunacy, of Scotland, in his report for 1879 , says of this asylum that "it was entered and traversed almost from end to end without summoning a servant or requiring any door to be unlocked; only three wards - two female and one male - were locked." In two other Scottish asylums for the insane this plan has been adopted. In the Barony Asylum, at Lenzie, near Glasgow, under charge of Dr. James Rutherford, every door of the institution is unlocked, allhough it contains four hundred and fifty patients.

When Dr. Tuke took care of Saughton Hall institution, he carried out the same system of treatment, and in his report for 1879 he says that there have been no escapes and no attempts at escape; that patients who used to stand at the doors, on the watch for a chance to get out, no longer do so; that many whose intellects were but slightly disturbed, and who have recovered, have expressed their gratitute to him for the relief experienced by the change from locked to unlocked doors; that this system has had an educational influence on all the inmates, so that it is now possible to give greater liberty to all than before. Certicin select cases are allowed to go on parole.

All this, surely, is a new, interesting, and almost incredible advance on the reforms of Pinel, Hill, and Connolly; it is a higher stage in the evolution of the management of the insane. Pinel broke the chains of the insane, took off the manacles. To-day, we go farther; unlock the doors.

I visited this Saughton Hall institution, and found it difficult to believe the gentleman who showed me over the place, when he said that it was an insane asylum. In external appearance, in internal arrangements, in the attendants, in the manner of the innates, in the furniture and arrangement of the rooms, there was nothing that suggested an asylum or a hospital ; it was more like a gentleman's delightful country residence, with open wiudows and doors, and ample and attractive grounds, beautified in the English style with varieties of shrubbery and flowers. I said to myself, This is the poetry of insanity, one might be willing to become insane, if he could be treated here.

In this asylum, and in others of similar character in Great Britain, it is the custom to have the patients, dur. ing the summer season, reside in villas by the sea-side, where they remain for a month or two, during July and August, and with most satisfactory results. The sea-side home of Saughton Hall institution is seventeen miles from Edinburgh. Thus it will be seen that the insane in England, who have the means to do so, live like gentlemen and ladies, with their summer and their winter residences, with proper liberty, and supplied not only with the necessities, but also with the luxuries of life.

Fifthly. The best asylums of Europe are not enormous or imposing buildings, but a series or collection of small or moderate-sized unimposing cottages or houses. In Europe, as in America, alienists began by placing the insane in gigantic palaces, and there, as here, they are finding out that with the increase of insanity, which could not have been anticipated either here or there, there must also be a change in the method of the construction and arrangement of asylums, although many large buildings remain.

'The institution at Alt Scherbitz has six or eight cottages, a small distance from each other, each cottage being about the size of a moderate country home, - all plain brick buildings, pleasing in appearance outside, and comfortable in reality inside. The Ruyal Edinburgh Asylum is composed of five houses, separated by a considerable distance; between the so-called "East House" and "Craig House" there is a space of almost a mile. It is believed and asserted that this splitting up of large buildings into a number of small ones, and this scattering the insane over a wider area than has been the custom formerly, is an immense practical advantage for all classes of lunatics. It allows them variety of employment; it allows seclusion for those who wish to be secluded; it gives change of scene and environment, so needful for sane and insane.

Sixthly. The methods of treating the insane in and out of asylums that have been most satisfactory in Europe can be and will be introduced in this country; in spite of and in the face of certain practical difficulties.

The chief of these difficulties is the nature of our political system, the motto of all political purties being, as you know, The spoils belong to the spoiler. Whatever can be obtained from the State is so much gain to the individual. Offices are the wages that we pay those who obtain offices for us.

Lunacy reform is, therefore, on one side, a branch of civil-service reform, and must rise and fall with it.

Oue of the Chancellor's Visitors in Lunacy told me that he had a salary of seventy-five hundred dollars, that his position was a life one, that he could be removed only by the joint action of both houses of Parliameut and the consent of Her Majesty. But as we have, on the whole. good men appointed on our health boards, with exceptions now and theu, it is fair and right and rational to hope that we shall have, on the whole, good men appointed on the central supervising commissions when we get the legislation.

This practical difficulty, therefore, grave as it may 
be, though it should not be forgotten, and must always be considered. is yet not to be auxiously or discouragingly feured. The first need of lunacy reform in this country is the creation of a mixed board of government commissioners in each State.

Yet another practical difficulty, not always referred to in these discussions, is that of getting as good offcers and attendants at small salaries as can be obtained in Europe for the same salaries. In all departments of activity in Furope we find men of much ability, native or acquired, filling humble or badly rewarded stations, who, in this land, might be making themselves wealthy and illustrious. This fact, the result of limited geographical area and excess of competition, is an advantage to those who seek for attendants or companions for the insane, or for superintendents of asylums. A moderate amount of money will purchase a far higher order of talent, and insure greater devotion, there than here. In the Saughton Hall institution they adopt. the plan of having educated, cultured ladies, in reduced circumstances, as companions for the wealthy insane. The duty of these companions is to accompany the patients in their drives and walks, be with them constantly in the drawing-rooms, to supervise, in a degree, the nurses, and, in some instances to sleep with those under their charge; and from this plan results of the most satisfactory character have been gained. In this country it would be far more difficult to find rultivated ladies who would be willing to take such positions.

In the treatment of the insane outside of asylums, by general practitioners and students of the nervous system, there has probably been as much advance in this country as abroad; and especially in the treatment of various morbid states of the nervous system that often lead to insanity there has been nowhere such satisfactory progress as here. This is the philosophical method of combating insanity : treating the insane before they are insane; arresting candidates for lunacy before they have stepped on the threshold of the asylum.

In regard to private asylums, concerning which Dr. Bucknill has lately written with so much vigor, these two facts must be admitted: that the system is liable to abuse or to suspicion of abuse, even under the central supervisory commissions, but that they would appear to be in a degree almost, if not quite, a necessity, with which we cannot entirely dispense.

In this respect, as in all respects, we are to study Europe, not to imitate it; what is good we are to keep, what is evil we are to reject; the chances for improvement by invention and discovery we are to resolutely occupy. 'To aid all these processes of scientific advance in the study of insanity, and in the management of the insane, this society has been organized, and will be maintained.

\section{RECEN'T AMERICAN ANATOMY ACTS.}

. BY EDWARD MUSSey HaRTWell, M. A.,

Fellow of the Johns Hopkins University.

THE Massachusetts anatomy act of 1831 was productive of results in two directions: it lightened the burdens of the teachers of anatomy in that State, and it led to the enactment of similar laws in other States. Connecticut passed a liberal act, modeled on that of Massachusetts, June 5, 1833, but repealed the same
June 5, 1834. New Hampshire legalized anatomy in 1834 , but rescinded its action in 1842 . Micligan passed " an act to facilitate the study of anatomy" March 9, 1844, but repealed it April 7, 1851. New York is entitled to the place of honor next to Massachusetts on the list of States which have consistently endeavored to promote anatomical science. The New York law of April 1, 1854, has never been repealed; on the contrary, it has been improved, notably by the amendatory act of June 3,1879 .

Referring to the Massachusetts law of 1831 , as amended in $184 \tilde{5}$, Dr. John C. Warren says : "The superintendent of the House of Industry opposed great difficulties to the execution of this law; but he dying in 1847 an ample supply was obtained for the medical school afterwards, particularly in cousequence of the influx of Irish paupers and the great mortality among them." Concerning the working of the sume law Dr. George Hayward, writing in 1855, says: "The supply has not been, perhaps, as great as could be wished, but with the increase of population and pauperism this objection will pass away." We doubt if in the judgment of the auatomists of the Harvard Medical Scliool " this objection" has "passed away." We incline to the belief that "with the increase of population and pauperism" there has been at least an equal increase of demagogues, and that no class of men in Massachusetts have a more realizing sense than have its anatomists of the relation existing between eternal vigilance and the price of liberty.

The city government of Boston, November 3, 1869 , ordered "that permits be issued by the city clerk, until otherwise ordered, to the surgeons of the Harvard Medical School to take the dead bodies of such persons dying at Deer Island, or the House of Correction, the County Jail, or City Hospital, as may be required to be buried at the public expense." The statutory restrictions concerning the delivery of unclaimed bodies are embodied in the remainder of the ordinance. The anatomists of Bultimore, Washington, and New Orleans might fairly consider this Boston ordinance a liberal one, for they are still obliged to dissect without a legal warrant, or not at all. On the other hand, in Germany or France, where for years the dissecting-rooms have been furnished with the unclaimed dead by the police, this ordinance would unquestionably be considered imperfect and illiberal.

It is unfortunate that American anatomists are forced to dance attendance upon public functionaries for "permits," as they are thereby put in the false position of seeking as a personal favor what ought to be furnished them for the furtherance of the public welfare. Possibly the time is not yet ripe for the Massachusetts anatomists to demand that the unclaimed dead of Springfield, Fall River, Worcester, Lowell, in short, the entire State, as well as of Boston, should be delivered to them at their dissecting-rooms; but such a consummation is none the less devoutly to be wished for. Massachusetts led off in legalizing the dissection of bodies required to be buried at the public expense. Would that she might inaugurate an administrative reform which should prevent the present wasteful decomposition of valuable material at the bottom of graves, and preclude the necessity which requires one who is bent on thoroughly learning practical anatomy in all its branches to seek the anatomical institutes of Europe!

The most elaborate, the most liberal, and also the 